\title{
A Robótica Educacional na Perspectiva das Metodologias Ativas
}

\author{
Maria Aparecida de Faria da Silva ${ }^{1}$, Márcia Gonçalves de oliveira ${ }^{2}$ \\ ${ }^{1}$ SEMED - Secretaria Municipal de Educação Vila Velha - ES - Núcleo de Ensino de \\ Robótica (NERO) \\ ${ }^{2}$ Centro de Referência em Formação e Educação a Distância - (CEFOR/IFES) \\ cidadfaria72@gmail.com, clickmarciaegmail.com
}

\begin{abstract}
The contemporary school has before it a great dilemma: How to promote one of method teaching motivating and relevant to the learning process? How to make students the agents of development itself? Faced with this reality, we highlight Educational Robotics as an instrument that offers several possibilities to enhance and facilitate the learning process. It can permeate interdisciplinary in an attractive way, facilitating the understanding of different knowledge, aligning theory and practice. In this way, students actively participate in the creation of a robot (idealization, assembly and programming) and in this process they will develop skills such as: collaboration, creativity, autonomy, critical sense, teamwork and responsibility. Within this vision, this article presents an experience report of how robotics fits as an effective tool in the perspectives of active methodologies for education.
\end{abstract}

Resumo. A escola contemporânea tem diante de si um grande dilema: Como promover um de método ensino motivador e relevante ao processo de aprendizagem? Como tornar os alunos agentes do próprio desenvolvimento? Diante dessa realidade, destacamos a Robótica Educacional como um instrumento que oferece várias possibilidades para potencializar e facilitar o processo de aprendizagem. Ela pode permear a interdisciplinaridade de forma atrativa, facilitando a compreensão de diferentes conhecimentos, alinhando a teoria e a prática. Dessa forma, os alunos participam ativamente nas etapas de criação de um robô (idealização, montagem e programação) e nesse processo eles vão desenvolvendo habilidades como: colaboração, criatividade, autonomia, senso crítico, trabalho em equipe e responsabilidade. Dentro dessa visão, este artigo apresenta um relato de experiência de como a robótica se enquadra como um instrumento efetivo na perspectiva das metodologias ativas para a educação.

\section{Introdução}

A evolução tecnológica que estamos presenciando na atualidade traz uma reflexão sobre a realidade da educação e a necessidade de mudanças que permitam um redirecionamento capaz de atender às aptidões das novas gerações de estudantes, desde seu início educacional, permitir-lhes o desenvolvimento de conhecimentos e habilidades para um futuro em que a tecnologia passa por desdobramentos contínuos. 
O processo de ensino-aprendizagem deve, dessa forma, envolver diversos autores na construção de conhecimentos e uma metodologia que ofereça uma opção de ensino motivadora. Moran (2015) Moran (2015) assinala que "a melhor forma de aprender é combinando equilibradamente atividades, desafios e informação contextualizada" essa perspectiva hoje está englobada nas metodologias ativas de aprendizagem.

Entre as muitas ferramentas pedagógicas da metodologia ativa está a robótica educacional e, segundo Schuhmacher (2018), ela "propõe explorar e ensinar conhecimentos científicos, a partir do uso de sucatas (...) e outras tecnologias", Essa proposta de ensino permite construção de protótipos e programação, tirando o estudante da inércia tornandoo um agente do seu desenvolvimento escolar e de sua aprendizagem. A robótica educacional alinha, dessa forma, o conhecimento teórico à prática e instiga os estudantes a buscarem respostas em muitas outras disciplinas para desenvolverem seus projetos. A concepção de uma resposta a problemas reais leva ao estudante o desenvolvimento do raciocínio lógico, a pesquisa, a criatividade, fomenta parcerias e interliga conhecimentos.

Considerando esses aspectos, essa pesquisa pretende descrever a robótica educacional como um instrumento pedagógico na perspectiva das metodologias ativas, capaz de oferecer possibilidades a aprendizagem em diversas disciplinas, por seu aspecto multidisciplinar, facilitando a visualização da teoria através da prática, promovendo assim a aprendizagem e o desenvolvimento cognitivo, motor e social.

Essa abordagem ganha relevância ao retratar a utilização da robótica educacional como instrumento pedagógico capaz de promover ambientes de aprendizagem no qual o estudante se torna autor e exerce uma participação prazerosa. A apresentação da metodologia e a experiência de ensino da robótica educacional poderá despertar na comunidade acadêmica o interesse pela temática, promovendo novos estudos na área.

\section{A Proposta de Pesquisa na Robótica Educacional}

O presente artigo tem como proposta a pesquisa de caráter bibliográfico, com fundamentação teórica, apoiada na pesquisa documental com utilização de livros, publicações periódicas em revistas, e pretende fazer relatos de experiências com características descritivas para embasar abordagem da Robótica Educacional como instrumento pedagógico nas metodologias ativas e sua funcionalidade em promover um processo de aprendizagem de forma lúdica e atrativa.

Os relatos aqui descritos retratam a experiência vivenciada por professores que atuam no programa de robótica educacional implantada nas escolas municipais de ensino fundamental II, no município de Vila Velha - ES. A abordagem dos dados é do tipo qualitativo e envolvem elementos como: Observação do desenvolvimento dos participantes nas aulas de robótica e nas aulas curriculares.

\section{A Robótica Educacional e as Metodologia Ativas}

Metodologia de ensino pode ser considerada como um procedimento didático para facilitar o processo de aprendizagem. Já a metodologia ativa, por sua vez, destaca a utilização métodos de ensino eficazes, que estimulam a iniciativa dos alunos para oportunizar a aprendizagem. Segundo Lima (2017) as metodologias ativas promovem pró-atividade, comprometimento no processo educacional e vinculação da aprendizagem aos aspectos significativos da realidade. A robótica educacional entra nesta perspectiva como um instrumento a ser utilizado em promoção de um processo de aprendizagem dinâmico e ativo. Para Ribeiro et al. (2018) as metodologias ativas possibilitam maior 
VIII Congresso Brasileiro de Informática na Educação (CBIE 2019)

Anais do XXV Workshop de Informática na Escola (WIE 2019)

integração nas interações entre professor-aluno e a aplicação dessas metodologias pode favorecer a autonomia do educando, despertando a curiosidade, estimulando tomadas de decisões individuais e coletivas.

A experiência vivenciada no programa de robótica implantado nas 13 escolas municipais de Vila Velha - ES (quantitativo em 2019) mostra que o processo de ensino utilizado está ancorado em pelo menos quatro vertentes das Metodologias Ativas para a aprendizagem, de acordo com a tabela elaborada por Ribeiro et al (2018), como mostradas abaixo (Tabela 1):

Tabela 1. Metodologias Ativas aplicadas na Robótica Educacional em Vila Velha - ES

\begin{tabular}{|l|l|}
\hline METODOLOGIAS ATIVAS & USO NA ROBÓTICA EDUCACIONAL \\
\hline $\begin{array}{l}\text { Aprendizagem Baseada em } \\
\text { Projetos (ABP); Problema } \\
\text { Based Learning (PBL) }\end{array}$ & $\begin{array}{l}\text { Construção e o manuseio do objeto de conhecimento, desenvolvendo projetos com a utilização } \\
\text { da robótica para resolverem problemas reais da sociedade. Essa experiência permite-lhes o } \\
\text { contato direto com a aprendizagem e as ciências envolvidas no desenvolvimento do projeto. }\end{array}$ \\
\hline Métodos de Caso; Study Case & $\begin{array}{l}\text { Estimula os alunos a pensarem e descobrirem, de forma ativa, soluções para os dilemas } \\
\text { apresentados. Na concepção do projeto, alunos e professores fazem levantamento de dados } \\
\text { para definirem como vão oferecer respostas ao problema apontado. }\end{array}$ \\
\hline $\begin{array}{l}\text { Pesquisa Ação } \\
\text { Intervencionista }\end{array}$ & $\begin{array}{l}\text { Uso das pesquisas para aprimorar o processo de aprendizagem. A pesquisa gera dados e } \\
\text { informações importantes na elaboração do projeto. Permite a avaliação e correção nas situações } \\
\text { de erros e acertos. }\end{array}$ \\
\hline Sala de Aula Invertida & $\begin{array}{l}\text { O conteúdo e as instruções são estudados preteritamente, a sala de aula se torna o local para } \\
\text { trabalhar conteúdos já estudados, realizando atividades práticas. Essa metodologia é muito } \\
\text { utilizada no laboratório de robótica concretizando o conhecimento pretérito. }\end{array}$ \\
\hline
\end{tabular}

A robótica educacional aplicada com base nas Metodologias Ativas tem a finalidade de aumentar o rendimento na aprendizagem, a partir da prática com utilização de objetos de Aprendizagens (OAs) no desenvolvimento social e cultural dos alunos. Cambruzzi e Souza (2015) afirmam que "os OAs, principalmente os computacionais, tornaram-se nas últimas décadas uma importante estratégia pedagógica para atrair a atenção dos alunos", no caso da robótica na educação o objeto de aprendizado é o robô e sua construção e programação exige uma combinação de muitos conhecimentos permitindo a visualização e a concretização do conhecimento.

\section{Relato de Experiência}

Para participar da I Mostra de Robótica das escolas municipais de Vila Velha, no ano de 2017, no primeiro ano do programa de robótica educacional, a UMEF Antônio Pinto Rodrigues elaborou com os alunos do $5^{\circ}$ ano, que participavam no programa, o projeto da "Luminária Sustentável" para abordar a reutilização de material descartável e empreendedorismo. O projeto foi desenvolvido com o objetivo de despertar nos alunos a conscientização quanto o descarte adequado e reaproveitamento de material descartável. Essa conscientização se faz necessário devido a realidade vivida por parte dos alunos da escola, que residem em uma área próxima a um rio onde o descarte de lixo é feita nele.

Na confecção da luminária foi utilizado colheres descartáveis, já a iluminação e música foram programadas com o Arduino. A luminária traz a proposta de iluminação musical para eventos, atendendo a perspectiva empreendedora e sustentável do projeto, visando despertar nos alunos maior participação na sua comunidade e a promoção de crescimento pessoal e coletivo. Os alunos desenvolveram, durante a elaboração do projeto, uma nova visão sobre o espaço onde vivem, repensando o seu papel na sociedade e na elaboração do próprio futuro. Houve também desenvolvimento quanto a utilização de computadores, pois a maioria dos alunos não tinham computador em casa. Ao longo 
VIII Congresso Brasileiro de Informática na Educação (CBIE 2019)

Anais do XXV Workshop de Informática na Escola (WIE 2019)

do ano escolar houve relatos de outros professores evidenciando maior produtividade dos alunos do programa nas aulas regulares. Observou-se melhoria nas relações sociais e aumento da autoestima. Como professora, de tecnologia atuando no programa de Robótica Educacional, percebi que um elemento colaborou para isso, a apresentação do projeto na Mostra de Robótica, quando os próprios alunos demonstraram a funcionalidade da Luminária. Eles se prepararam na escola e em casa, quanto a oratória, comportamento e sociabilização, a maioria das famílias destes alunos se envolveram nessa trajetória e isso motivou-os com maior confiança em seu potencial.

O projeto foi apresentado na I Mostra de Robótica em um shopping do município, juntamente com os demais projetos desenvolvidos nas dez escolas inseridas no programa de Ensino de Robótica em 2017, conforme a Tabela 2.

Tabela 2. Projetos desenvolvidos para I Mostra de Robótica

\begin{tabular}{|c|c|c|}
\hline PROJETO & $\begin{array}{l}\text { TECNOLOGIA } \\
\text { do PROJETO }\end{array}$ & OBJETIVOS PEDAGÓGICOS \\
\hline Luminária Sustentável - UMEF A. P. R. & Arduino & $\begin{array}{lccccc}\begin{array}{l}\text { Conscientização sobre descarte de lixo, reciclagem } \\
\text { empreendedorismo. Lógica de programação. }\end{array} & & & \\
\end{array}$ \\
\hline PianoCalc-UMEF U. A. & Arduino & $\begin{array}{l}\text { Facilitar a aprendizagem das operações matemática. Lógica de } \\
\text { programação. }\end{array}$ \\
\hline $\begin{array}{l}\text { O SmartEnergy - UMEFTI S. J. de M. } \\
\text { C. }\end{array}$ & Arduino & Conscientização de uso dos recursos naturais. Lógica de programação. \\
\hline $\begin{array}{l}\text { Prática Sustentável e Sócio } \\
\text { Educacional - UMEF T.T. }\end{array}$ & Arduino & $\begin{array}{l}\text { Conscientização quanto ao descarte de lixo eletrônico. Lógica de } \\
\text { programação. }\end{array}$ \\
\hline Semáforo Inteligente - UMEFTI T. N. & Arduino & Trânsito seguro para deficientes e idosos. Lógica de programação. \\
\hline $\begin{array}{l}\text { Separador e Contador de Moedas - } \\
\text { UMEFTI W. M. F. }\end{array}$ & Arduino & Operações matemáticas e finanças. Lógica de programação. \\
\hline $\begin{array}{l}\text { Lego - Robôs seguidores de linha } \\
\text { Hidroponia - Horta. UMEF M. C. }\end{array}$ & $\begin{array}{l}\text { Lego } \\
\text { Arduino }\end{array}$ & $\begin{array}{l}\text { Cálculos matemáticos e programação. Cultivo de horta hidropônica. } \\
\text { Lógica de programação. }\end{array}$ \\
\hline Projeto IMC - UMEF D. R. & Arduino & Conscientização do controle da obesidade. Lógica de programação. \\
\hline $\begin{array}{l}\text { Robótica e artes, designer sem limites } \\
\text { - UMEFTI R. A. da S. C. }\end{array}$ & Arduino & $\begin{array}{l}\text { Composição artísticas - cores, formas, componentes eletrônicos e } \\
\text { sucatas. Lógica de programação. }\end{array}$ \\
\hline
\end{tabular}

Elaborado com Autorização do NERO - Núcleo de Ensino de Robótica/Secretaria Municipal de Educação Vila Velha - ES

Outra grande experiência foi o interesse de um aluno com Deficiência Intelectual em participar no grupo de robótica, de início o maior temor foi quanto a relação dele com os outros alunos e depois como ele se apropriaria dos conhecimentos de programação e montagem dos protótipos na elaboração do robô. Quão grande foi a surpresa, os outros alunos foram acolhedores e se tornaram, por iniciativa própria, "monitores", colaborando para o desenvolvimento do colega. Em poucos meses este aluno, com necessidades especiais, estava acompanhando perfeitamente, respeitando as suas limitações, as propostas para elaboração de projetos executados nas aulas de robótica. É possível ver nesta experiência que a participação deste aluno promoveu desenvolvimento intelectual e social em toda a equipe de robótica.

Neste mesmo período houve relatos de participação efetiva de alunos da Educação Especial no programa de robótica em outras escolas. Estes relatos descrevem o desejo destes alunos pelo uso da tecnologia e o encanto que os robôs exercem sobre eles. Também foi observado desenvolvimento cognitivo, motor e social (estes dados requerem mais estudos na forma qualitativa e quantitativa).

\section{Resultados Obtidos}

$\mathrm{Na}$ experiência vivida a partir da implantação da robótica educacional na ótica das metodologias ativas como um instrumento pedagógico no município de Vila velha - ES, 
têm mostrado que os alunos, que estão participando ativamente no projeto, têm apresentado desenvolvimento em diversos aspectos. Mas o principal benefício encontrase no fato que eles estão amadurecendo na responsabilização por sua formação educacional. Estão tendo mais acesso à tecnologias avançadas, mudando assim sua visão quanto ao próprio futuro. A participação no programa é garantida respeitando o interesse individual pela tecnologia, na responsabilidade no uso dos equipamentos, na frequência e no desenvolvimento escolar.

O programa de robótica educacional nas escolas também proporciona aos estudantes a oportunidade de participação em eventos de robótica, desde que o projeto desenvolvido seja inscrito e selecionado. Dessa forma, o contato com outros estudantes e outras experiências no ensino da robótica permitiu maior desenvolvimento e perspectivas aos alunos e professores.

\section{Conclusão}

Ao longo deste estudo buscou-se explicar a robótica educacional como um instrumento pedagógico, facilitador, no processo de aprendizagem. Como principal resultado podemos apontar que a robótica na educação apresenta um caminho possível a ser assumido e usado como uma estratégia aplicada as Metodologias Ativas para o desenvolvimento e a assimilação de conhecimento, capaz de promover maior participação e interesse por parte dos alunos, dentro e fora do espaço escolar. Enfatizamos, no entanto, que se faz necessário, antes fazer uma adequação na metodologia assumida no ambiente educacional e na formação dos professores preparando-os para o uso da tecnologia envolvida na robótica educativa, considerando o seu caráter interdisciplinar.

Evidenciamos ainda a importância de continuidade desta pesquisa para dar aprofundamento e oferecer dados mais consistentes de caráter bibliográfico, qualitativo e quantitativo, contextualizado na pesquisa de campo, permitindo a mensuração e a validação da aplicabilidade da robótica como instrumento nas metodologias ativas para a educação, e os benefícios que este método oferece para o processo de aprendizagem, tanto no aspecto intelectual como social.

\section{Referências}

CAMBRUZZI, Eduardo; DE SOUZA, Rosemberg Mendes. Robótica Educativa na aprendizagem de Lógica de Programação: Aplicação e análise. In: Anais do Workshop de Informática na Escola. p. 21. 2015.

LIMA, Valéria Vernaschi. Espiral construtivista: uma metodologia ativa de ensinoaprendizagem. Interface-Comunicação, Saúde, Educação, v. 21, p. 421-434, 2016.

MORAN, José. Mudando a educação com metodologias ativas. Coleção Mídias Contemporâneas. Convergências Midiáticas, Educação e Cidadania: aproximações jovens, v. 2, n. 1, p. 15-33, 2015.

RIBEIRO, E.B. et al. in: Dimas. A. p. B.; Rocha, D.A. (Orgs). Neurociência, Educação e Metodologias ativas: um estudo de revisão. SENPEX. p. 878 -891, 2018.

SCHUHMACHER, E. et al. Ensino de robótica educacional livre como metodologia ativa para a promoção da aprendizagem significativa em ciências e tecnologias. Acesso 